\title{
LANGUAGE QUALITY IN SCIENTIFIC JOURNALS: WHOSE RESPONSIBILITY?
}

\author{
Marcin Kozak
}

\begin{abstract}
Is it journal editors' role to decide whether the language of the manuscripts submitted to their journals is fine? Among so many duties they have, this one seems to be all-too-often forgotten, or ignored, affecting the quality of scientific publications. Their indifference can also lead to unnecessary arguments between authors and reviewers, or to situations in which the authors have no idea what to do. Left alone, authors seldom win, even if they are right. This paper discusses whose role it is to keep writing quality of journal articles.
\end{abstract}

Keywords: academic writing, peer review, academic journals

\section{Introduction}

Who is responsible for the quality of language of a scientific manuscript? The simplest and intuitive answer is: its authors. But as is with the quality of science, we should append this one-element list with reviewers and editors.

"Editors of scientific publications are in the best position to understand both the value and difficulty of simple writing," state Vuong and Napier [2017]. I concur, but at the same time I feel that not all editors would. Some may prefer running away from the responsibility of taking care of their scientific journals' language [Kozak, 2008a].

In Core competencies for scientific editors of biomedical journals: consensus statement, we do not see any direct mention of language [Moher et al., 2017]. The only related competency is "Check the content of manuscripts submitted for publication for completeness, logic, and consistency," under the core competency "Evaluate the scientific rigor and integrity of manuscripts and make editorial decisions after consideration of reviewers' and other editors' comments." Although related to writing, this competency only indirectly touches upon this aspect. Given so many directly stated things to take care of, many editors might actually ignore such indirect hints.

Global science requires that all scientists use the same language so that they can understand their peers. It's no longer Latin, nor is it French-it is English that made the lingua sciencia in the twentieth century, makes it now, and is likely to make it in the future.

Marcin Kozak, Department of Media, Journalism and Social Communication, University of Information Technology and Management in Rzeszow, Sucharskiego 2, 35-225 Rzeszów, Poland, ORCID 0000-0001-9653-3108 
Almost all scientists can understand written English, but many non-native English scientists have problems writing in it. This should not surprise: Learning how to write well is difficult even in one's native language, not to mention a foreign one. What also does not come as a surprise is that so many manuscripts are rejected for language reasons.

Sometimes, however, such rejections are overkill, with the emphasis on how bad the writing is being over the top. Even very well-written texts by experienced native English authors happen to be criticized based on "poor language," especially when the reviewers have failed to notice a native English speaker among the co-authors and assumed non-native English authors cannot write well (see Kozak [2008b] and the discussion published in the same issue). Of course, sometimes even native authors fail to write well enough, and then such criticism is justified-but it is not when the text is well written.

The truth is, many non-native English scientists feel themselves unfairly treated only because their English is not perfect. On top of that, many of them do not know English well but must still publish in it. How to deal with these issues is a challenging question. I would like to offer you a sensible answer, but I cannot. Younger researchers are a little luckier, having started learning English early on in their primary education. But most of them are still far behind their native English colleagues, for whom English is, well, their word and their world.

A non-native English speaker myself, I have had problems with understanding many of the manuscripts I have reviewed, and not surprisingly, most of them were written by non-native English speakers. Sometimes the quality of writing is so bad that the only thing I can do is write, "I'm sorry, I just don't know what you mean." In these sad moments, I understand native English reviewers. I understand why they are upset with unclear and unidiomatic writing. I understand that faced with such writing too often, they may feel that most non-native English speakers are just a pain-and nothing more.

But at the same time, I do understand non-native English authors feeling depressed when reading such comments. I've been there. I know the feelings of frustration. I know the lack of self-esteem that is likely to follow. Thus, I always try to sound encouraging when criticizing their language. I am afraid, however, that many reviewers do not.

Let us return to Core competencies for scientific editors of biomedical journals: consensus statement, where we can read that the scientific editor should "[d]emonstrate skill, tact, diplomacy, confidentiality, and professionalism in interactions with authors, peer reviewers, readers, staff (if applicable), and other relevant individuals or groups, particularly when concerns or disputes arise regarding the peer review and publication process" [Moher et al., 2017]. Thus, when a reviewer criticizes the English language when it is actually fine, the journal editor should step in, guiding and guarding both the author and the reviewer.

But what is bizarre is that the most discouraging comments related to language can come not from natives but from non-natives. What is even more bizarre, sometimes such comments come from reviewers who clearly do not know English too well. As an author, I have received several comments like "your english must improves." As an editor to quite a few journals, I have seen many more of them; so did Matarese and Shashok [2018].

Criticizing language and writing is easy when the manuscript is indeed in poor shape, with plenty of grammatical mistakes, strangely chosen words, and unclear sentences. But where is the border between the good and the bad, between the acceptable and the unacceptable? And who is to make that decision?

\section{Journal editors: their role in this game}

The above-mentioned bizarre behavior of non-native English reviewers is particularly striking. I see two likely reasons behind it. First, such reviewers might have problems with understanding the text they are reviewing, in their opinion a perfect indication that 
there is something wrong with the language being used. Secondly, some think that their knowledge of English is quite good even though, well, it isn't.

Imagine that one of the reviewers of my manuscript writes that "The languages must polish." I look into the editor's comments, but I find there no mention of this strange note. What does it mean? That the editor agrees with it? Or maybe the editor prefers me to address it? But how am I to respond? I don't think it would be wise to say, for instance, "Excuse me, Reviewer 2, but your English seems much worse than mine, so I don't think I should worry about your opinion," a shortcut to rejection-possibly via a rage-and-hatred route. So, maybe it's better to say, "Thank you very much for your comment. We have revised the whole manuscript throughout"? Most of the time, this is a wise thing to do indeed; many a time, unfortunately, such reviewers respond with something like "The manuscripts language have to still be throughout correcting." So, what to do?

The question that asks itself is this: Where was the editor, the one who passed me this comment without any mention? Leaving such comments uncommented seems to suggest that the editor agrees with them. But it's unlikely, so should I ask the editor what he or she thinks? Perhaps. But frankly, I do think that editors should do something before sending decision letters with such comments. Depending on the journal's policy, such a comment should be either removed (the editor should let the reviewer know about this) or commented on by the editor in the letter to the authors (e.g., "Reviewer 2 suggests the English language should be improved, but I do not think this is quite an issue, so feel free to ignore it").

Glonti and colleagues [2019] conducted a qualitative study among editors of biomedical journals, trying to find out what they thought about the roles reviewers and editors play. Throughout their article, you will find nothing about guarding the quality of language. But what the participants stressed was that "peer reviewing should go beyond the mere technical assessment of manuscripts and thus has also a supportive role." Reviewer comments like those above do not fall into the category of supportive comments. But what can the editor do? The authors write, "They [editors] have the authority to 'override peer reviewers recommendations' and 'ignore their opinion', if necessary, thereby directly or indirectly exerting influence on authors to modify their manuscripts."

\section{So, whose responsibility is it?}

Reviewers can suggest polishing the language, but it is the editor who should verify such claims, setting the border between the acceptable and the unacceptable. Journal editors should face the truth: It is their role to help their journals' authors, supporting their associate (or whatever they are called) editors, reviewers, and readers. It is also they who should be responsible for the overall style of their journals.

It is also journal editors who should react when a reviewer asks for heavy editing (such as "practically each sentence requires revision") when light editing-if any at allwould be enough. And, especially, it is they who should do something when a reviewer whose English is worse than that of the authors claims that "a English language must to improve." When the editor reacts, at least by letting the authors know they should not worry about it, such a comment will unlikely do any harm. According to Matarese and Shashok [2018], "journal editors should be able to either provide authors with useful feedback on the language (e.g., by endorsing or overruling reviewers' complaints) or delegate this responsibility to an appropriately skilled reviewer or editorial staffer."

On one hand, journal editors should have proficient language skills [Jawaid and Jawaid, 2017, Glonti et al., 2019]. But on the other, this is not always the case. Some journal editors do not feel up to being responsible for their journals' language. The most common situation-and a rather understandable one-is when they themselves are non-native English speakers. Unfortunately, I am afraid that it does not make much of a difference: The writing quality in their journal is still their responsibility. In such a situa- 
tion, they can and should look for help among the other editors; or find a new editor who would help them out with language issues; or even consider hiring a language editor, whose sole responsibility would to be take care of writing quality.

\section{Conclusion: Three perspectives}

An author's position. As an author, I wish to be guided by the editor of a journal to which I am submitting my manuscript-but also to be protected against unfair comments regarding the English in my manuscripts. Non-native English authors should not be left alone in their struggles against unfair reviewers.

A reviewer's position. As a reviewer, I equally wish to have the journal editor's support. I like to review in a comfortable situation in which I know that the editor guards the language gates. I can suggest that the language might require attention, and that's it-let the editor decide whether this is true or not, even if I am sure it is. If the language is difficult to understand, I would pass such information to the editor and let him or her check. Only in extreme situations of completely incomprehensible language should a reviewer say so directly to the author. But actually, such a situation should never happen: The editor should reject such a paper without sending it to reviewers.

An editor's position. Such an approach would make authors' and reviewers' lives easier, but it wouldn't always do the same for journal editors. It might give them more work, actually: They would have to pay attention to the language of the manuscript as well as to what the reviewers say about it. If the reviewers are critical, the editor must decide whether that's true or not, and if not, the editor should react accordingly. This approach would likely make their work better organized and more efficient, in effect improving their journals' quality.

In science, if you want to convey a message, interest your readers, and convince them of something, then writing matters [Kozak and Hartley, 2019]. If poorly written, even great research can go unnoticed, or be misunderstood, or forgotten. But if written in an interesting way and thus offering a pleasant read, even poor research can find its way to the reader.

For this very reason, I do think that it's natural for all journal editors to care about the quality of writing in their journals. This is one way to make their journals well received and do the job of disseminating science. Ignoring writing quality means ignoring the multidimensionality of the journal's quality, a path towards depletion instead of development.

And so, for journal editors, the whole situation means one thing: They are to guard this important aspect of academic writing-writing.

\section{References:}

GLONTI, K., BOUTRON, I., MOHER, D., \& HREN, D. (2019). Journal editors' perspectives on the roles and tasks of peer reviewers in biomedical journals: a qualitative study. BMJ open, 9(11).

KOZAK M. (2008a). On journals' copyediting. Current Science, 94(8), 963.

KOZAK M. (2008b) A call from a non-native speaker: don't look at my affiliation. European Science Editing, 34(4), 100; with discussion on pages 100-104 and in the subsequent issues of the journal.

JAWAID, S. A., \& JAWAID, M. (2017). Professional competencies required for Editors of Biomedical Journals. Pakistan Journal of Medical Sciences, 33(5), 1050-1052.

KOZAK, M., \& HARTLEY, J. (2019). Academic science writing: an inconsiderate genre? European Science Editing, 45(3), 69-71.

MATARESE, V., \& SHASHOK, K. (2018). Improving the biomedical research literature: insights from authors' editors can help journal editors define and refine their core competencies. F1000Research, 7.

MOHER, D., GALIPEAU, J., ALAM, S., BARBOUR, V., BARTOLOMEOS, K., BASKIN, P., ... \& DEEKS, J. (2017). 
Core competencies for scientific editors of biomedical journals: consensus statement. BMC Medicine, 15(1), 167.

VUONG Q.H., NAPIER N.K. (2017). Academic research: The difficulty of being simple and beautiful. European Science Editing, 43(2), 32-33. 